\title{
Crown Rust Development and Selection for Virulence in Puccinia coronata f. sp. avenae in an Oat Multiline Cultivar
}

\author{
M. L. Carson, United States Department of Agriculture-Agricultural Research Service, Cereal Disease Laboratory, \\ St. Paul, MN 55108
}

\begin{abstract}
Carson, M. L. 2009. Crown rust development and selection for virulence in Puccinia coronata f. sp. avenae in an oat multiline cultivar. Plant Dis. 93:347-353.

Crown rust, caused by Puccinia coronata f. sp. avenae is the most important disease of cultivated oat in North America. Numerous race-specific $(P c)$ genes for crown rust have been found in Avena spp. but this type of resistance has not been durable when used in oat cultivars. Increasing diversity for resistance within a crop by the use of multiline cultivars or varietal mixtures has been proposed as a means of achieving durable resistance to highly variable pathogens such as $P$. coronata f. sp. avenae. Multiline cv. E77 was evaluated over multiple seasons in the University of Minnesota buckthorn nursery in St. Paul. Buckthorn (Rhamnus cathartica, the alternate host of $P$. coronata) supports a sexually recombining, highly diverse crown rust population in the St. Paul nursery. Crown rust severity on flag leaves was measured multiple times on E77 and its 10 component lines during grain filling. Single-urediniospore isolates taken from crown rust samples during early stages of the epidemic and at the end of the epidemic were tested for virulence on the 10 component lines of E77 in greenhouse seedling tests. Crown rust development was reduced in E77 compared with the weighted mean of the component lines at all stages of the crown rust epidemics. The mean virulence of single-urediniospore isolates tended to increase late in the epidemic on E77. These data suggest that multilines may select for complex virulence or "super races" and any resistance effect may not be durable.
\end{abstract}

Oat crown rust, caused by Puccinia coronata $\mathrm{f}$. sp. avenae, is considered to be the most serious disease of oat (Avena sativa L.) in North America (27). It is distributed worldwide but is most damaging where heavy nightly dews occur in conjunction with moderate to high temperatures during the growing season. Under ideal conditions, crown rust can result in complete crop failure. In the United States, the mean estimated loss to crown rust over the 10-year period of 1996 to 2005 was 2.2 and 3.2\% for the upper Midwest (South Dakota, North Dakota, and Minnesota) and the southern plains (Texas and Louisiana), respectively (D. L. Long, personal communication). Losses in individual years and states were as great as $6 \%$ in the upper Midwest (Minnesota in 1996) and 20\% in the southern plains (Louisiana in 1997).

The use of host genetic resistance has been the primary means of controlling crown rust of oat. Breeders have primarily relied on race-specific seedling genes that are expressed as some form of hypersensi-

Corresponding author: M. L. Carson

E-mail: mcarson@umn.edu

Accepted for publication 21 November 2008.

doi:10.1094/PDIS-93-4-0347

This article is in the public domain and not copyrightable. It may be freely reprinted with customary crediting of the source. The American Phytopathological Society, 2009. tive reaction. Initially, resistance genes used were found in cultivated hexaploid oat, A. sativa. As these genes were deployed in oat cultivars, corresponding virulence in the crown rust population increased rapidly, to the point that virulence to most of these genes is nearly fixed in the North American population. Later efforts at finding effective resistance turned to exploiting genes found in the wild hexaploid animated oat, A. sterilis, which is the basis of most resistance in current oat cultivars. As these genes have been deployed, of probability, respectively.

${ }^{y}$ Data from 2005 and 2006 combined.

${ }^{\text {z }}$ E77 (actual) - E77 (predicted). corresponding virulence has increased in the crown rust population, such that the effective life span of a resistant oat cultivar is often 5 years or less. Breeders and geneticists are now turning to diploid species, particularly black oat, A. strigosa, as sources of new resistance genes, but introgression of resistance into hexaploid oat is difficult due to differences in ploidy levels and the lack of homology of chromosomes between the two species (1). The University of Wisconsin-Madison and the Agriculture Agri-Foods Canada-Winnipeg oatbreeding programs have released cultivars with crown rust resistance genes from $A$. strigosa.

Increasing intracrop diversity for disease resistance by the use of multiline cultivars or varietal mixtures has been proposed as a means of achieving more durable resistance to highly variable pathogens such as $P$. coronata f. sp. avenae $(4,5,22,29)$. Multilines reduce the amount of initial inoculum and the rate of epidemic development because only a fraction of the pathogen population is virulent upon any component of the multiline $(4,5,11,23)$. Disease spread is reduced because resistant plants act as a barrier to spore dispersal. Induced resistance caused by infection with a mixture of compatible and incompatible races may also serve to reduce disease in multilines $(11,23)$. In addition to reducing disease development, multilines or cultivar mixtures may prevent or greatly delay the occurrence of "super races" with virulence

Table 1. Mean area under the disease progress curves (AUDPC) of the oat multiline cultivar E77 and its 10 component lines during crown rust epidemics in the St. Paul buckthorn nursery, 2004-06

\begin{tabular}{|c|c|c|c|c|}
\hline Entry & 2004 & 2005 & 2006 & $2005+2006^{y}$ \\
\hline CI 9169 & 520 & $478 \mathrm{a}$ & $400 \mathrm{ab}$ & 439 a \\
\hline CI 9170 & 520 & $455 \mathrm{a}$ & $418 \mathrm{a}$ & $437 \mathrm{a}$ \\
\hline CI 9172 & 380 & $424 a b c$ & $362 a b$ & 393 a \\
\hline CI 9176 & 72 & $169 \mathrm{de}$ & $97 \mathrm{e}$ & $133 \mathrm{de}$ \\
\hline CI 9178 & 360 & $444 \mathrm{ab}$ & $319 b c$ & $381 \mathrm{ab}$ \\
\hline CI 9181 & 340 & $493 \mathrm{a}$ & $395 a b$ & 444 a \\
\hline CI 9285 & 48 & 205 de & $51 \mathrm{e}$ & $128 \mathrm{e}$ \\
\hline CI 9286 & 700 & $344 \mathrm{c}$ & $401 \mathrm{ab}$ & $373 a b$ \\
\hline CI 9287 & 48 & $135 \mathrm{e}$ & $69 \mathrm{e}$ & $102 \mathrm{e}$ \\
\hline CI 9290 & 372 & $353 \mathrm{bc}$ & $244 \mathrm{~cd}$ & $298 \mathrm{bc}$ \\
\hline E77 (PI552970) & 252 & $243 \mathrm{~d}$ & $196 \mathrm{~d}$ & $219 \mathrm{~cd}$ \\
\hline E77 $(\text { Act }- \text { Pred })^{z}$ & -113 & $-135 * * *$ & $-108 * *$ & $-122 * * *$ \\
\hline
\end{tabular}

${ }^{x}$ Means followed by the same letter are not significantly different at the $P=0.05$ level of probability based on the Fisher's least significant difference test; ** and *** signify that the mean AUDPC of the multiline E77 is significantly less than that predicted from the means of its component lines based on single degree-of-freedom contrasts in the analyses of variance at the 0.01 and 0.001 levels 

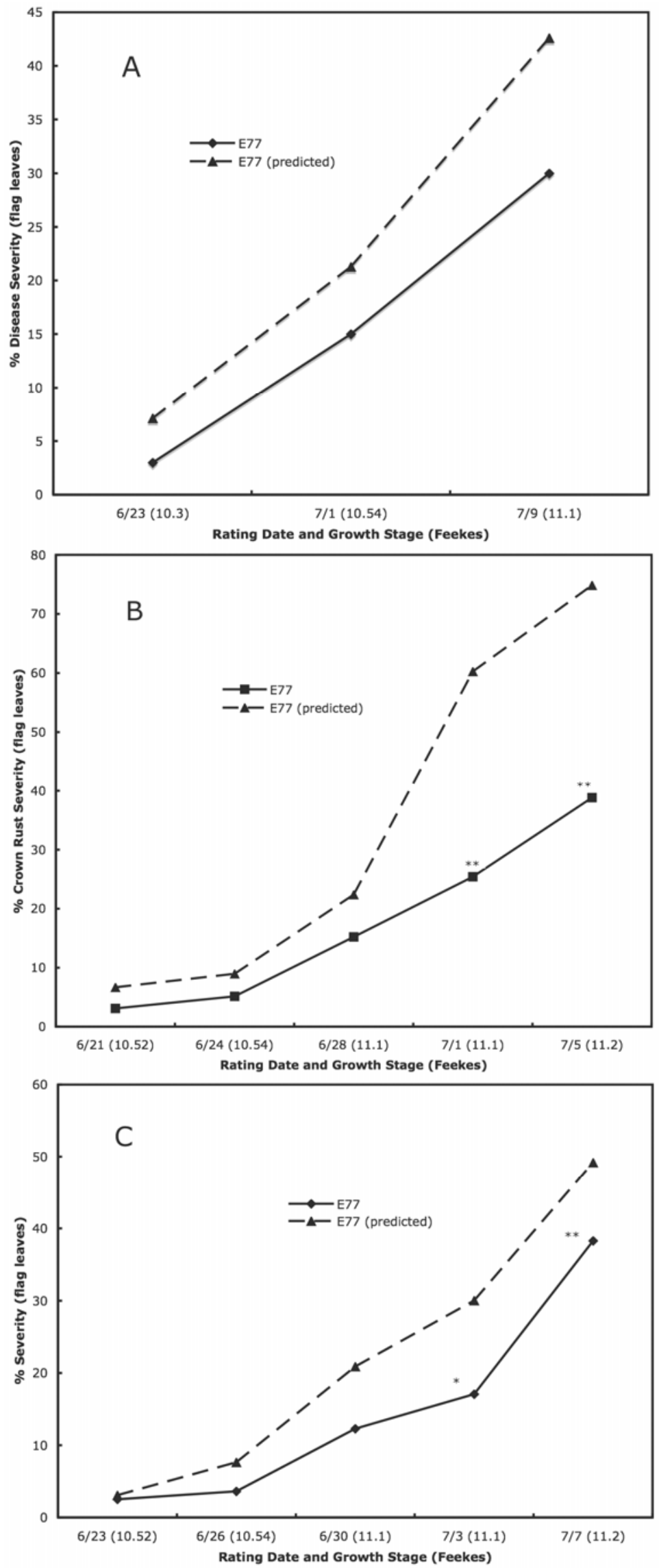

Fig. 1. Actual and predicted disease progress curves of crown rust on the E77 multiline in the St. Paul, MN buckthorn nursery in A, 2004; B, 2005; and C, 2006. Asterisks: * and ** indicate that the actual disease severity is significantly less than predicted at the 0.05 and 0.01 level of probability, respectively, based on single degree-of-freedom contrasts in the analysis of variance of the 2005 and 2006 data. to multiple components of the multiline or mixture $(3,12)$. The objectives of this research were to (i) determine the efficacy of a complex multiline cultivar in reducing crown rust development when exposed to a highly complex, sexually recombining pathogen population and (ii) determine if the multiline favors simple or complex races during the course of an epidemic.

\section{MATERIALS AND METHODS}

Seed of the oat multiline E77 (PI552970), developed by Iowa State University in the 1970s (10), and its 10 nearisogenic component lines were obtained from the United States Department of Agriculture National Small Grains Germplasm Collection in Aberdeen, ID. Seed was increased in St. Paul to obtain a sufficient amount of seed for subsequent experiments. Plots of E77 and its component lines were planted in the 2004, 2005, and 2006 growing seasons in the buckthorn nursery at St. Paul, MN. This nursery has been in continuous use for oat crown rust research since the 1950s. The nursery consists of oat plots planted between parallel hedges of common buckthorn (Rhamnus cathartica L.). A random sample of oat straw containing telia of $P$. coronata $\mathrm{f}$. sp. avenae was collected from the buckthorn nursery during the previous growing season and placed on the buckthorn hedges every spring as leaves emerged on the hedges. The resulting pycnial infection and subsequent production of aecia and aeciospores provide inoculum for the oat nursery. The resulting crown rust population in this nursery is a highly diverse, sexually recombining population. Plots of E77 and its component lines consisted of 16 and 8 rows each, respectively, $2.4 \mathrm{~m}$ long and spaced $0.3 \mathrm{~m}$ apart. All plots were bordered by four rows of wheat (cv. Chris) in all directions. In 2004, the experiment consisted of a single replicate of E77 and its component lines. In 2005 and 2006, experiments consisted of a randomized complete block with two replicates. The 2004 and 2006 experiments were planted on 4 May and the 2005 experiment on 22 April. In 2004, crown rust severity on flag leaves was visually estimated on whole plots three times at 8-day intervals, starting at heading. Crown rust severity on flag leaves was estimated five times at 3- to 4day intervals in 2005 and 2006, starting at the completion of flowering at the top of the head (Feekes scale 10.5.2) and ending at the hard kernel stage (Feekes scale 11.3). At each sampling date in 2005 and 2006, 5 and 20 random flag leaves were rated in each plot of the component lines and E77, respectively. Crown rust populations in each plot were sampled twice each year, once at early stages of the epidemic and once late in the season, just prior to crop maturity. To ensure that urediniospores collected actually originated from uredinia on the collected leaves, leaf sam- 
ples with crown rust pustules were placed for 2 to $3 \mathrm{~h}$ in a dew chamber to induce germination of urediniospores, removed from the dew chamber, and allowed to air dry, thus killing any germinating urediniospores. Urediniospores were then collected 1 day later from uredinia that had resporulated overnight. In 2004, 50 single uredinial isolates were sampled from each plot at each sampling time for a total of 1,100 isolates. In 2005 and 2006, 25 isolates were sampled from each replicate plot for a total of 50 isolates from E77 and each component line on each of the two sampling dates for a total of 1,100 isolates per year. Single uredinial isolates were tested for virulence on seedlings of the 10 component lines of E77 in greenhouse tests. Differences in virulence frequencies between early and late samples were compared with Fisher's exact test using the web-based Simple Interactive Statistical Analysis software (available online from Quantitative Skills, Consultancy for Research and Statistics, Hilversum, The Netherlands). Also, the mean virulence (average number of component lines on which isolates were virulent) was compared between early and late samples from each treatment using $t$ tests. Disease severity data from each rating date and area under the disease progress curve (AUDPC) values from 2005 and 2006 experiments were analyzed with analysis of variance (ANOVA). The multiline effect was calculated as the difference between disease severity on E77 and the mean severity on the 10 component lines weighted by their contribution to E77 (10), and tested for significance as a single degree-of-freedom contrast in the ANOVA. The absolute frequency of isolates virulent on all 10 component lines of E77 late in each growing season was estimated by multiplying the relative frequency (proportion) of those isolates in plots of the component lines and E77 by the final disease rating in those plots. The predicted absolute frequency in E77 of isolates virulent on all 10 component lines was calculated by weighting the absolute frequency of such isolates on each component by the contribution of that component to E77.

\section{RESULTS}

Crown rust developed rapidly in the research plots each year of the study. Disease severities on flag leaves reached $50 \%$ or greater on the more susceptible component lines by the hard kernel stage of development. The majority of the 10 component lines of E77 were quite susceptible to the crown rust population in the buckthorn nursery, but CI9285, CI9287, and CI9176 were consistently more resistant than the other component isolines (Table 1). The multiline E77 consistently sustained less disease (AUDPC) than what would be predicted based on the weighted mean of its 10 components. The average multiline
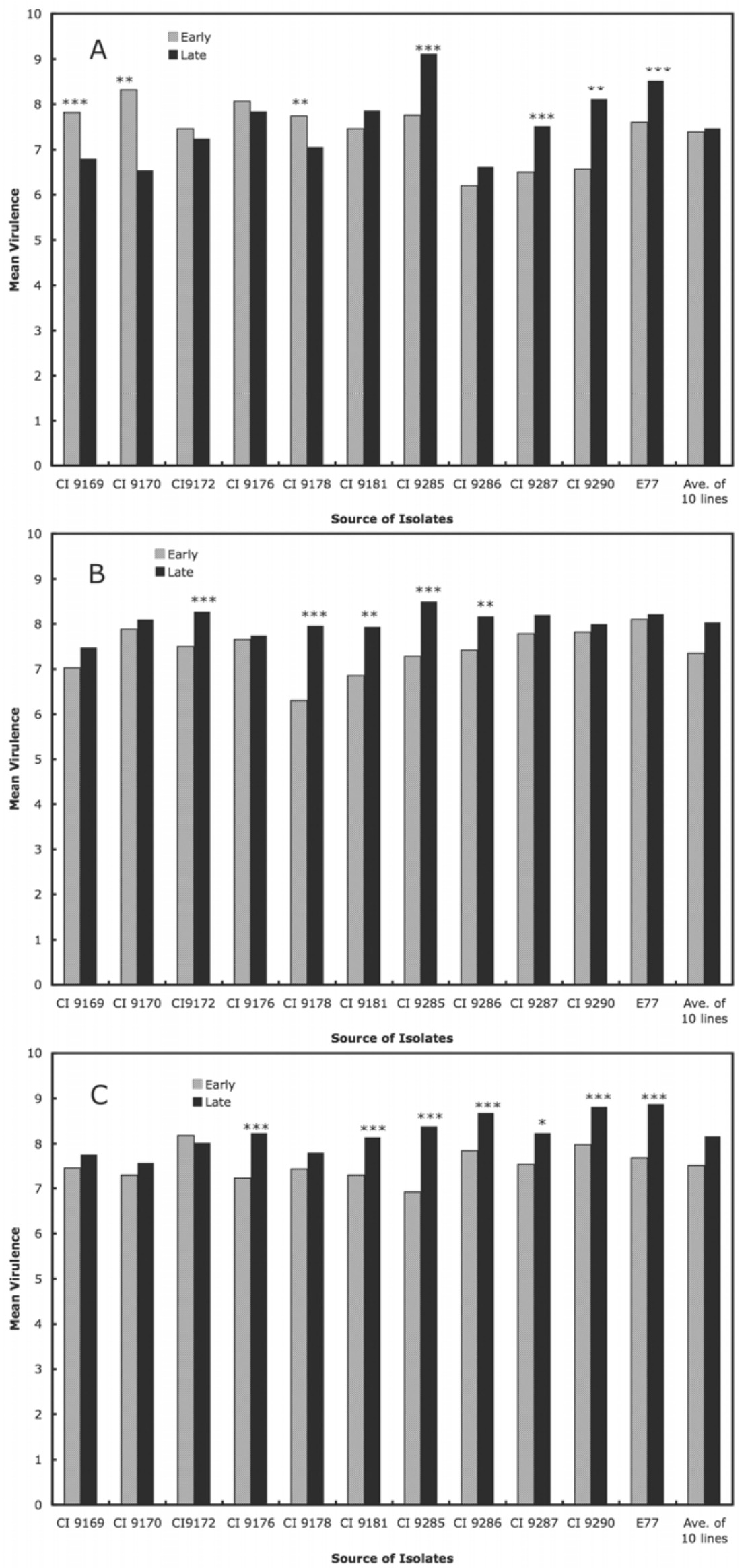

Fig. 2. Mean virulence of Puccinia coronata isolates sampled from E77 and its 10 component lines early and late in the crown rust epidemics in A, 2004; B, 2005; and C, 2006 in the St. Paul, MN buckthorn nursery; *,**, and *** indicate that the mean virulence differed significantly between early and late samples at the $0.05,0.01$, and 0.001 level of probability, respectively, based on $t$ tests. 

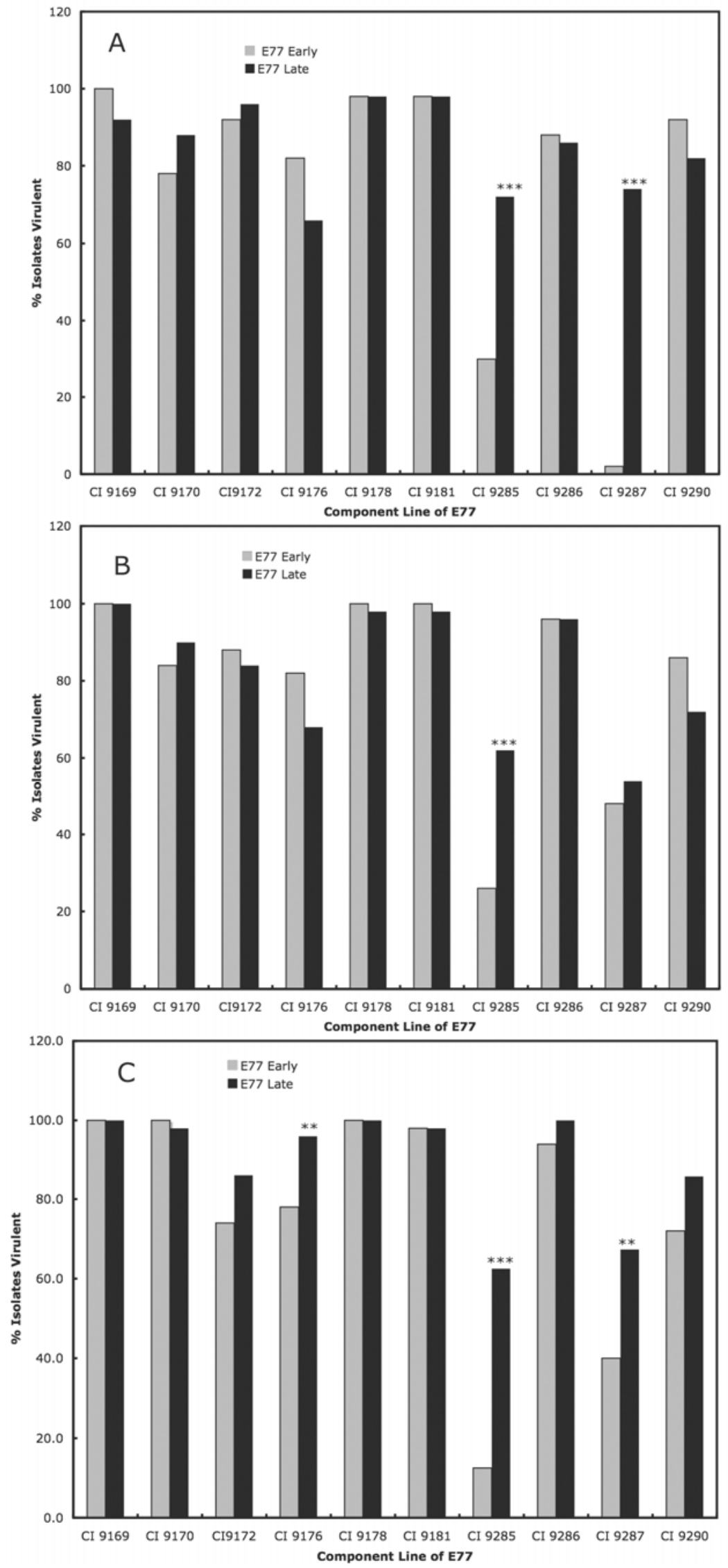

Fig. 3. Percentage of Puccinia coronata isolates from E77 virulent on each of its 10 component lines. Plots were sampled early and late in the crown rust epidemics in A, 2004; B, 2005; and C, 2006 in the St. Paul, MN buckthorn nursery; *, **, *** indicate the percentage of isolates virulent on a given component line of E77 differed significantly between early and late sampling dates at the $0.05,0.01$, and 0.001 level of probability, respectively, based on Fisher's exact tests. effect, or percent reduction in AUDPC on E77 versus the weighted mean of its component lines, was 31,36 , and $35 \%$ in 2004 , 2005 , and 2006, respectively. The multiline effect tended to increase as the epidemics progressed and became statistically significant for the last two ratings in the replicated trials of 2005 and 2006 (Fig. 1).

The mean virulence of single-uredinial isolates sampled from the trial plots tended to increase during the course of the epidemics in 2005 and 2006 trials, but results from 2004 were mixed (Fig. 2). In the 2005 and 2006 trials, the mean virulence of isolates from plots of E77 and its component lines increased numerically in all cases but one when samples taken early in the epidemic were compared with those taken late in the epidemic. In 2004, mean virulence significantly decreased in three of the component lines and significantly increased in three of the component lines and E77. Mean virulence of isolates significantly increased in CI9285 by late in the season in all three years of the study. Virulence complexity of single-uredinial isolates sampled from E77 increased by late in the epidemic in all 3 years of the study; however, this increase was only significant in 2004 and 2006 (Fig. 2). The frequency of virulence to CI9285 increased significantly in E77 in all 3 years of the study while the frequency of virulence to CI9287 and CI9176 significantly increased in 2004 and 2006, respectively (Fig. 3). The relative frequency of singleuredinial isolates sampled from E77 virulent upon all 10 of its component lines increased late in the epidemic in all 3 years (Fig. 4). This increase was significant in 2004 and 2006 but not in 2005 . At the late sampling date in 2006, fully $30 \%$ of isolates from the multiline were virulent on all 10 component lines of E77. Similarly, isolates from CI9285 that were virulent on all 10 component lines significantly increased by late in the season in all 3 years of the study (Fig. 4). The discrepancy of the 2005 data from the other 2 years may be explained at least partially by the fact that the early sampling date in 2005 was taken later in the development of the crown rust epidemic compared with 2004 and 2006, and some selection for increased virulence may have already occurred by that early sampling date. The absolute frequency of isolates virulent on all 10 component line of E77 at the end of the epidemic was greater on E77 than either the mean of the component lines or that predicted for E77 based on absolute frequencies observed in the component lines (Fig. 5). In only one component line (CI9286) in 1 year (2006) was the absolute frequency of isolates virulent upon all 10 component lines greater than that observed on E77.

\section{DISCUSSION}

Despite the high degree of susceptibility of most of the component lines of E77, the 
high degree of corresponding virulence in the population of $P$. coronata, the high levels of inoculum in the buckthorn nursery, and the relatively small plot sizes used in the study, crown rust severity was consistently reduced in the multiline compared with the weighted mean of its components. Although this level of disease reduction (approximately 30\%) is likely of limited practical value in reducing losses to crown rust, the high disease pressure in the buckthorn nursery may represent a "worstcase" scenario. More useful levels of disease reduction might well occur in a typical grower's field situation. However, in the north-central states of the United States, $R$. cathartica (common buckthorn) is common and widely distributed, often in close proximity to oat fields. It would not be unusual for portions of oat fields adjacent to buckthorn plants, either in wooded areas or in fence lines, to be exposed to high external inoculum levels of a highly diverse population of $P$. coronata, as occurs in the St. Paul buckthorn nursery. Even in southern United States winter oat production areas where the alternate host does not occur, inoculum levels can reach very high levels because the long growing season allows for many more asexual reproductive cycles of $P$. coronata than would occur in the relatively short growing season in the northern spring oat region.

The level of disease control observed in this experiment is not directly comparable with that from other studies of oat multilines against crown rust where disease progress was measured as cumulative spore densities (not disease severities) over plots where inoculum of defined races was introduced artificially, and multiline performance was compared with a susceptible check cultivar and not the component isolines $(24,25)$. However, the level of crown rust control (approximately 30\%) is within the range reported by Smithson and Lenne (28), who summarized published studies on the effects of cultivar mixtures on a diverse array of cereal and common bean diseases.

Of greater concern is the apparent selection for increased virulence in the multiline. The increasing virulence late in the season, particularly isolates virulent on all 10 component lines, may not bode well for the durability of the resistance of the multiline. Even when the multiline effect in reducing the overall pathogen population is taken into account, the absolute frequency of isolates virulent on all 10 component lines is greater in the multiline than in the component lines at the end of the epidemics. Presumably, continued cultivation of a multiline over many years and hectares could result in an increase in super races of $P$. coronata capable of potentially eroding the effectiveness of the multiline in reducing disease. The presumption that multilines or cultivar mixtures select for simple races virulent on only one or a few components is based on the assumption that
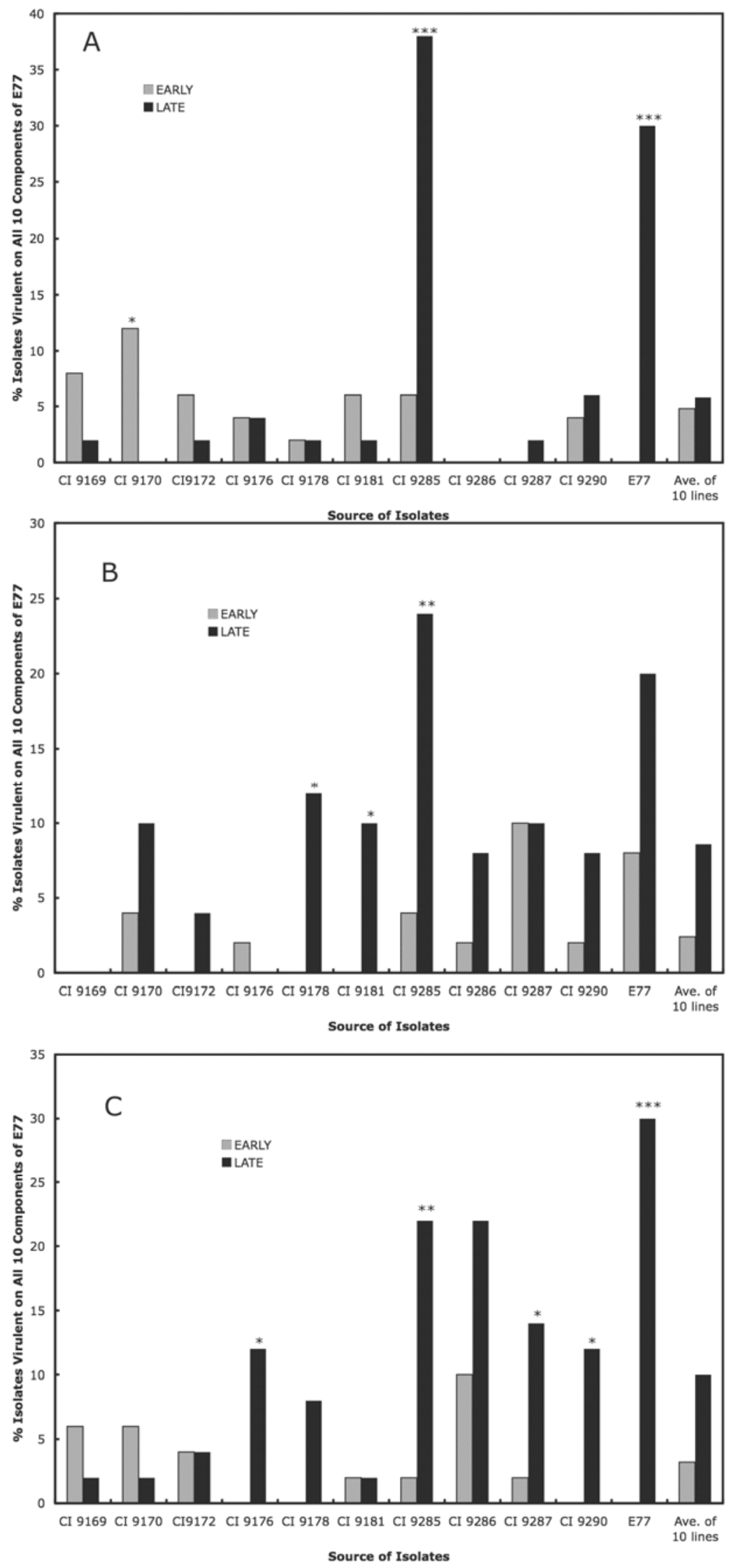

Fig. 4. Percentage of Puccinia coronata isolates from E77 and its 10 component lines virulent on all 10 component lines. Plots were sampled early and late in the crown rust epidemics in A, 2004; B, 2005; and C, 2006 in the St. Paul, MN buckthorn nursery. *, **,*** indicate that the percentage of isolates virulent on all component lines of E77 differed significantly between early and late sampling dates at the $0.05,0.01$, and 0.001 level of probability, respectively, based on Fisher's exact tests. 
there is a fitness cost to unnecessary virulence $(3,12,17,18,22)$. Evidence for a fitness cost to unnecessary virulence in $P$. coronata f. sp. avenae populations in agroecosystems is equivocal. Population surveys in the United States and elsewhere indicate that isolates of $P$. coronata are quite capable of carrying numerous unnecessary virulences without any apparent cost in fitness $(7,19,20)$. The mean viru-
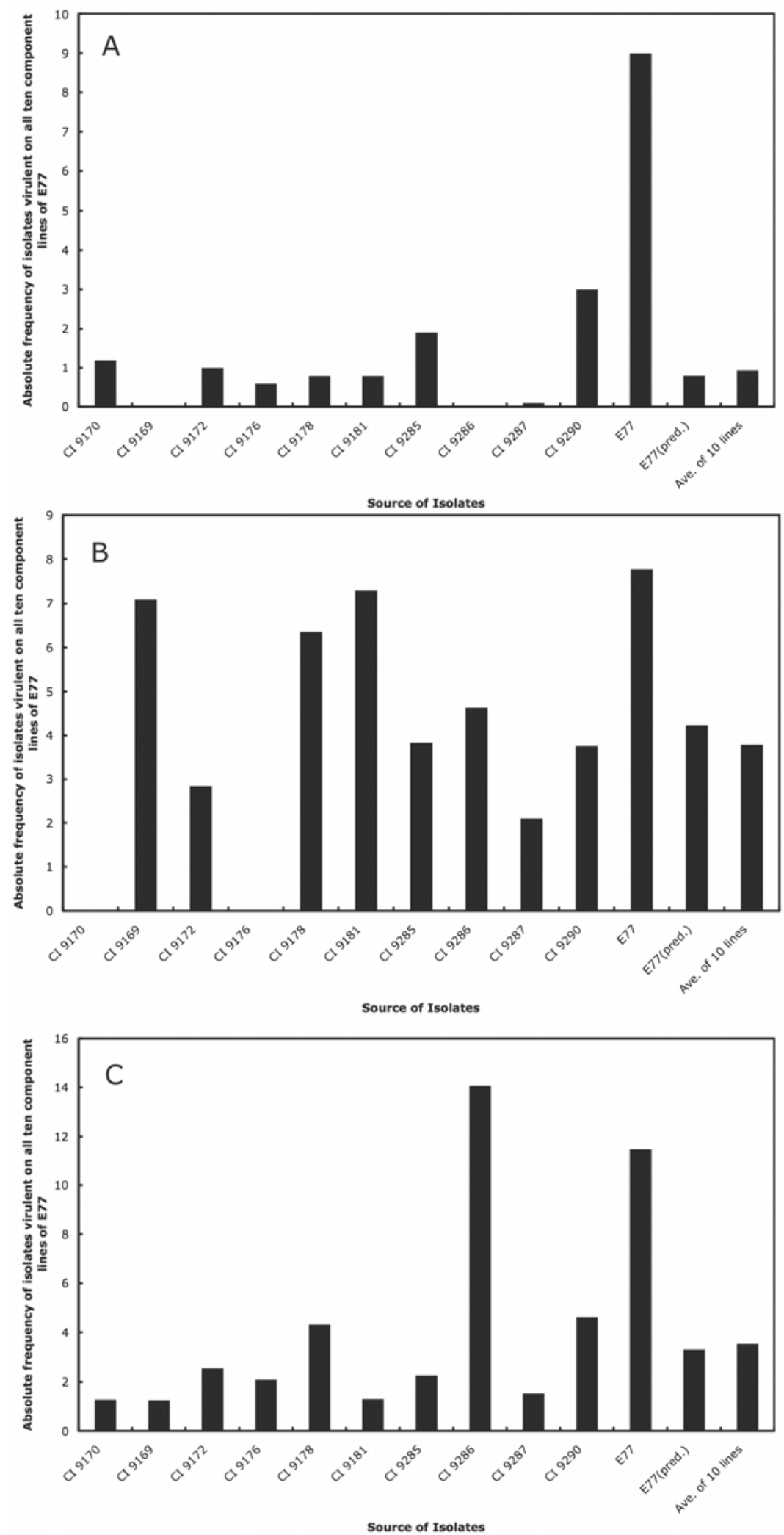

Fig. 5. Observed absolute frequency of Puccinia coronata isolates virulent from E77 and its 10 component lines virulent on all 10 component lines at the end of crown rust epidemics in A, 2004; B, 2005; and C, 2006 in the St. Paul, MN buckthorn nursery, as well as the predicted absolute frequency of those isolates from E77.

lence of the U.S. crown rust population has continued to increase unabated $(7,19)$. Bardin and Leonard (2), however, found evidence of selection in $P$. coronata against virulence to specific $P C$ genes after 10 generations of asexual reproduction on seedlings of a completely susceptible cultivar. It is not clear how these results would translate to a sexually recombining population in nature. If the apparent cost of virulence was due to the fitness of the genetic background in which virulence occurred as opposed to the virulence per se, then selection over multiple sexual generations should lead to an increase in fitness of those virulent races. It is also possible that some sort of frequency-dependent selection or selection favoring heterozygosity at avirulence loci could explain the persistence of unnecessary virulence in crown rust populations (20). Simulation studies of the evolution of complex races in host mixtures by Lannou and Mundt $(17,18)$ show that the increase in frequency of complex races may be reduced by an increased cost of virulence, density dependence, focal distribution of initial inoculum, and differential adaptation to components of the host mixture. The level of selection against unnecessary virulence needed to prevent the buildup of complex races of $P$. coronata in an oat multiline in the buckthorn nursery is probably relatively high, given the shallow dispersal gradient of the disease and the general distribution of inoculum, and is probably higher than that found by Bardin and Leonard in oat crown rust (2).

Studies on selection for pathogen virulence in multilines or cultivar mixtures are limited. Browning and Frey (5) reported that populations of $P$. coronata $\mathrm{f}$. $\mathrm{sp}$. avenae from plots of multilines in Texas were more virulent and more diverse than populations from pure lines. Chin and Wolfe (8) found that virulence complexity increased in Blumeria graminis f. sp. hordei populations in mixed stands of three barley cultivars but, because the cultivar mixture effect reduced the absolute size of the pathogen population, the absolute frequency of complex races was reduced in the mixture compared with pure stands. Huang et al. (14) measured changes in virulence complexity of $B$. graminis $\mathrm{f}$. $\mathrm{sp}$. hordei populations during two growing season in barley mixtures planted as a random mix, one-row, or three-row mixtures. Virulence complexity increased over the growing seasons in all mixture plots but the rate was greatest in random mixtures where the potential effects of autoinfection were the least. Kolmer (16) measured selection in heterogeneous $P$. recondita $\mathrm{f}$. sp. tritici $(=P$. triticina $)$ populations over 12 asexual generations in three Thatcher wheat multilines containing 0 , 20 , and $50 \%$ susceptible Thatcher plants. Phenotypic diversity decreased significantly in all three multilines. Pathogen phenotypes virulent to three of the five 
resistance genes used in the multilines increased and predominated in all multilines by the end of the experiment. However, in a previous study (15), phenotypic diversity decreased and virulence to the same three resistance genes increased when the same heterogeneous population of $P$. triticina was selected for 12 generations on Thatcher, indicating that genes for fitness may be linked to those virulences.

One of the core concepts behind the use of multilines is that they will mimic what occurs in natural ecosystems, where an apparent equilibrium exists between a diverse host population and the pathogen population, such that disease levels are reduced and complex races do not predominate. The A. sterilis $-P$. coronata $R$. palestina pathosystem in Israel is cited as an example of such a situation (6). However, virulence surveys indicate that the mean virulence of races of $P$. coronata in Israel is often greater than that occurring in agroecosystems in the United States (20). So-called super races, capable of attacking most of the differentials, did not predominate in either country; however, P. coronata populations can clearly maintain a certain intermediate level of unnecessary virulence without any apparent penalty. There was also no correlation between mean virulence of $P$. coronata populations and the distribution of resistance in $A$. sterilis populations in Israel.

Although oat multilines developed by Iowa State University were at one time grown on up to 0.4 million ha in the United States (5), their use quickly declined and they are no longer grown to any extent. The reasons for this are probably manifold, but primary among them is that multilines could not compete agronomically with newer pure-line cultivars. Backcross breeding to develop the isoline components of multilines is, by definition, very conservative. By the time resistance genes have been successfully backcrossed into a cultivar and the multiline generated, the agronomic performance of the recurrent parent of the multiline has often become obsolete. Second, it is likely that, despite giving some measure of crown rust control, it may have paled in comparison with new cultivars with high (albeit short-lived) resistance to crown rust when first released. Browning and Frey (5) attributed their demise, in part, to their success in reducing crown rust inoculum in Iowa and, ironically, the demand or need for crown rust resistance. However, this reduction in inoculum may also be attributed to a dramatic decrease in oat acreage in the United States and efforts to eradicate buckthorn in Iowa during the same time period (5).

Enhancement of the durability of seedling resistance $(P c)$ genes to oat crown rust remains an elusive goal. There is nothing from previous experience of using $P c$ genes either singly or in combination in pure-line oat cultivars to indicate that fu- ture attempts will be any more durable. Although the use of defeated $P C$ genes in multiline or cultivar mixtures may offer some degree of control initially, the longterm durability of this "population resistance" is not supported by the data presented here. The apparent selection for complex races virulent on all components of a complex multiline such as E77 in a single growing season, coupled with the lack of any apparent fitness cost to complex virulence in $P$. coronata, strongly suggests that complex races could build up rapidly in response to widespread cultivation of an oat multiline. An attractive alternative for oat improvement programs is race-nonspecific, partial crown rust resistance. This type of resistance to crown rust has been recognized in cultivated hexaploid oat for many years $(13,21)$ but is not a part of most U.S. oat improvement programs. Selection for this type of resistance has been hampered due to difficulties in distinguishing it from combinations of race-specific seedling genes that are effective against most of the crown rust population, its relatively low heritability, its association with late maturity, and the poor agronomic performance of many of the sources of partial resistance. Partial resistance to crown rust in the oat breeding line MN841801 is apparently controlled by either two additive genes (9) or seven (four major and three minor) quantitative trait loci (QTL) (26). Molecular markers suitable for effective marker-assisted selection of QTL for partial resistance to crown rust in oat are currently lacking, but rapid developments in this area may remove impediments to its use in oat improvement.

\section{LITERATURE CITED}

1. Aung, T., Chong, J., and Leggett, M. 1996. The transfer of crown rust resistance Pc94 from a wild diploid to cultivated hexaploid oat. Pages 167-171 in: Proc. 9th Int. Eur. Mediterr. Cereal Rusts and Powdery Mildews Conf. Lunteren, The Netherlands. G. H. J. Kema, R. E. Niks, and R. A. Daamen, eds. Eur. Mediterr. Cereal Rust Foundation, Wageningen, The Netherlands.

2. Bardin, M., and Leonard, K. J. 2000. Selection against unnecessary virulence in Puccinia coronata. Acta Phytopathol. Entomol. Hung. 35:223-227.

3. Barrett, J. A. 1980. Pathogen evolution in multilines and variety mixtures. Z. Pflanzenkrankh. Pflanzenschutz 87:383-396.

4. Browning, J. A., and Frey, K. J. 1969. Multiline cultivars as a means of disease control. Annu. Rev. Phytopathol. 7:355-382.

5. Browning, J. A., and Frey, K. J. 1981. The multiline concept in theory and practice. Pages 37-46 in: Strategies for the Control of Cereal Disease. J. F. Jenkyn and R. T. Plumb, eds. Blackwell, Oxford.

6. Browning, J. A., Frey, K. J., McDaniel, M. E., Simons, M. D., and Wahl, I. 1979. The biologic of using multilines to buffer pathogen populations and prevent disease loss. Indian J. Genet. Plant Brdg. 39:3-9.

7. Carson, M. L. 2008. Virulence frequencies in oat crown rust in the United States from 2001 through 2005. Plant Dis. 92:379-384.

8. Chin, K. M., and Wolfe, M. S. 1984. Selection on Erysiphe graminis in pure and mixed stands of barley. Plant Pathol. 33:535-546.

9. Chong, J., 2000. Inheritance of resistance to two Puccinia coronata isolates in a partial resistant oat line MN841801. Acta Phytopathol. Entomol. Hung. 35:37-40.

10. Frey, K. J., Browning, J. A., and Simons, M. D. 1985. Registration of Multiline E76 and Multiline E77 oats. Crop Sci. 25:1125.

11. Garrett, K. A., and Mundt, C. C. 1999. Epidemiology in mixed host populations. Phytopathology 89:984-990.

12. Groth, J. V. 1976. Multilines and "super races": a simple model. Phytopathology 66:937-939.

13. Heagle, A. S., and Moore, M. B. 1970. Some effects of moderate adult resistance of oats. Phytopathology 60:461-466.

14. Huang, R., Kranz, J., and Welz, H. G. 1994 Selection of pathotypes of Erysiphe graminis $\mathrm{f}$. sp. hordei in pure and mixed stands of spring barley. Plant Pathol. 43:458-470.

15. Kolmer, J. A. 1993. Selection in a heterogeneous population of Puccinia recondita $\mathrm{f}$. $\mathrm{sp}$. tritici. Phytopathology 83:909-914.

16. Kolmer, J. A. 1994. Selection of Puccinia recondita $\mathrm{f}$. sp. tritici virulence phenotypes in three multilines of Thatcher wheat lines near isogenic for leaf rust resistance genes. Can. J. Bot. 73:1081-1088.

17. Lannou, C., and Mundt, C. C. 1996. Evolution of a pathogen population in host mixtures: simple race-complex race competition. Plant Pathol. 45:440-453.

18. Lannou, C., and Mundt, C. C. 1997. Evolution of a pathogen population in host mixtures: rate of emergence of complex races. Theor. Appl. Genet. 94:991-999.

19. Leonard, K. J. 2003. Regional frequencies of virulence in oat crown rust in the United States from 1990 through 2000. Plant Dis. 87:13011310.

20. Leonard, K. J., Anikster, Y., and Manisterski, J. 2004. Patterns of virulence in natural populations of Puccinia coronata on wild oat in Israel and in agricultural populations on cultivated oat in the United States. Phytopathology 94:505-514.

21. Luke, H. H., Chapman, W. H., and Barnett, R. D. 1972. Horizontal resistance of Red Rustproof oats to crown rust. Phytopathology 62:414-417.

22. Marshall, D. R., and Weir, B. S. 1985. Multiline varieties and disease control. Theor. Appl. Genet. 69:463-474.

23. Mundt, C. C. 2002. Use of multiline cultivars and cultivar mixtures for disease management. Annu. Rev. Phytopathol. 40:381-410.

24. Mundt, C. C., and Browning, J. A. 1985. Development of crown rust epidemics in genetically diverse oat populations: effect of genotype unit area. Phytopathology 75:607-610.

25. Politowski, K., and Browning, J. A. 1978. Tolerance and resistance to plant disease: an epidemiological study. Phytopathology 68:1177-1185.

26. Portyanko, V. A., Chen, G., Rines, H. W., Phillips, R. L., Leonard, K. J., Ochocki, G. E., and Stuthman, D. D. 2001. Quantitative trait loci for partial resistance to crown rust, $P u c$ cinia coronata, in cultivated oat, Avena sativa L. Theor. Appl. Genet. 111:313-324.

27. Simons, M. D. 1985. Crown rust. Pages 131 172 in: The Cereal Rusts: Vol. II. Diseases, Distribution, Epidemiology, and Control. A. P. Roelfs and W. R. Bushnell, eds. Academic Press, Orlando, FL.

28. Smithson, J. B., and Lenne, J. M. 1996. Varietal mixtures: a viable strategy for sustainable productivity in subsistence agriculture. Ann Appl. Biol. 1228:127-158.

29. Wolfe, M. S. 1985. The current status and prospects of multiline cultivars and variety mixtures for disease control. Annu. Rev. Phytopathol. 23:251-273. 